\title{
REKOMENDASI MODEL BISNIS INDUSTRI MUSIK POP DAN ROCK DI INDONESIA BERDASARKAN MODEL BUSINESS CANVAS
}

Ilham Maulana ${ }^{1} \&$ Andry Alamsyah $^{2}$

Prodi Manajemen Bisnis Telekomunikasi \& Informatika, Fakultas Ekonomi \& Bisnis, Universitas Telkom

email: mauliwang@gmail.com ${ }^{1}$, andrya@telkomuniversity.ac.id ${ }^{2}$

\section{ABSTRAK}

Perkembangan teknologi informasi dan komunikasi (TIK) dewasa ini menyebabkan perubahan strategi dan model bisnis pada Industri Musik Indonesia. Perubahan tersebut menuntut peningkatan kemampuan untuk beradaptasi terhadap teknologi dalam perencanaan model bisnis industri musik khususnya musik pop dan rock. Penelitian ini bertujuan untuk melihat pola bisnis Industri Musik di Indonesia menggunakan dengan menggunakan framework Business Model Canvas Osterwalder dan Pigneur yang akan dianalisis menggunakan SWOT Analysis Business Model Canvas untuk dapat melihat dan merekomendasikan pola Model Business Canvas Industri Musik di Indonesia. Pada paper ini akan dibahas model bisnis untuk penerbit musik dan penulis lagu agar dapat bertahan pada cepatnya perubahan era TIK saat.

Kata kunci : Model Bisnis, Model Bisnis Kanvas, Industri Musik, TIK 
JURNAL

MANAJEMEN

INDONESIA

Vol. 14. No. 2

Agustus 2014
Industri Musik adalah kegiatan kreatif yang berkaitan dengan kreasi/komposisi musik, pertunjukan musik, reproduksi musik, dan distribusi dari rekaman musik [1]. Industri musik memiliki berbagai saluran bisnis dimana salah satunya adalah penyebaran bisnis pada pasar digital. Segmentasi konsumen layanan berlangganan pada pasar musik digital meningkat dua pertiga menggantikan layanan download, video, dan saluran lainnya [2].

\section{Model Bisnis Kanvas Untuk Penerbit Musik}

\begin{tabular}{|c|c|c|c|c|}
\hline \multirow{2}{*}{$\begin{array}{c}\text { Key Partners } \\
\text { Penyedia Bahan Baku } \\
\text { Pabrik Produksi CD \& DVD } \\
\text { Operator Telekomunikasi }\end{array}$} & $\begin{array}{l}\text { Key Activities } \\
\text { Pemasaran } \\
\text { Art and Repertiore }\end{array}$ & \multirow[t]{2}{*}{$\begin{array}{l}\text { Value Propositions } \\
\text { Aliran Pop, Rock, dan Disco } \\
\text { CD \& DVD Berkualitas Tinggi }\end{array}$} & $\begin{array}{c}\text { Customer Relationships } \\
\text { Manajemen Ritel }\end{array}$ & \multirow[t]{2}{*}{$\begin{array}{c}\text { Customer Segments } \\
\text { Penikmat Musik } 14-21 \text { Tahun }\end{array}$} \\
\hline & $\begin{array}{c}\text { Key Resource } \\
\text { Musisi } \\
\text { Studio Rekaman }\end{array}$ & & $\begin{array}{c}\text { Channels } \\
\text { Internet } \\
\text { Jaringan Telekomunikasi } \\
\text { Toko Ritel } \\
\end{array}$ & \\
\hline \multicolumn{2}{|c|}{$\begin{array}{c}\text { Cost Structure } \\
\text { Produksi } \\
\text { Promosi }\end{array}$} & & \multicolumn{2}{|c|}{$\begin{array}{c}\text { Revenue Streams } \\
\text { Penjualan CD \& DVD }\end{array}$} \\
\hline
\end{tabular}

Gambar 1. Model Bisnis Penerbit Musik.

Pada perkembangan teknologi, terlihat pada gambar 1, Industri Musik di Indonesia menjual produk fisik berupa CD dan DVD walau pun saluran penjualan telah menyesuaikan dengan perkembangan teknologi. Indonesia lambat dalam mengadopsi strategi yang tepat untuk menghadapi perubahan yang diakibatkan oleh perkembangan teknologi. Hal tersebut terbukti pada tahun 2004, grup band Paterpan menjual album fisik mereka sebanyak 2,7 juta kopi [3], sedangkan pada saat yang bersamaan, negara - negara lain sedang mencari jalan keluar untuk mengatasi pola pembajakan musik. Saat ini, Aquarius Mahakam dinyatakan tutup karena telah merugi Rp. 40 juta setiap bulannya [4]. Menurut ASIRI, total penjualan dari tahun ke tahun hanya mengalami peningkatan pada tahun 2011 dan 2012 lalu kembali mengalami penurunan pada tahun 2013, sedangkan penjualan VCD dan Kaset selalu menurun dari tahun ke tahun. Penurunan penjualan menuntut perusahaan rekaman dan pelaku bisnis untuk segera mencari model bisnis yang tepat agar dapat mengatasi permasalah ini dan tidak hanya memperdebatkan dampak negatifnya.

Menteri Perdagangan Indonesia merilis "Rencana Pengembangan Ekonomi Kreatif 2009 - 2015" sebagai rencana pengembangan 14 subsektor di Industri Kreatif. Dalam rencana pengembangan tersebut, Industri Musik memiliki rantai nilai untuk alur kerja bisnis musik dimana perusahaan rekaman besar memegang peran penting dalam saluran distribusi yang luas untuk Industri Musik Indonesia. Musisi juga dapat secara mandiri mendistribusikan karyanya kepada konsumen. Keadaan ini tidak sesuai karena kurangnya dukungan pemerintah yang membuat perusahaan rekaman berusaha untuk tetap bertahan dan mencari jalan keluar untuk mendapatkan pangsa pasar digital sedangkan disisi lain, penjualan $\mathrm{CD}$ jatuh lebih cepat daripada kenaikan musik musik digital. Banyak musisi yang bersaing dalam industri ini, namun tidak diimbangi dengan pelaku bisnis yang mampu menampung dan menaungi bakat musisi menjadi profesional baik secara musik maupun bisnis. Ketimpangan tersebut menjadi penyebab lambatnya perkembang industri musik di Indonesia.

Model Bisnis Kanvas Untuk Musisi

\begin{tabular}{|c|c|c|c|c|}
\hline \multirow{2}{*}{$\begin{array}{l}\text { Key Partners } \\
\text { Radio } \\
\text { Stasiun Televisi } \\
\text { Label Rekaman }\end{array}$} & $\begin{array}{l}\text { Key Activities } \\
\text { Produksi Lagu }\end{array}$ & \multirow[t]{2}{*}{$\begin{array}{l}\text { Value Propositions } \\
\text { Album Live } \\
\text { Konser Musik }\end{array}$} & $\begin{array}{c}\text { Customer Relationships } \\
\text { Manajemen Musisi } \\
\text { Member }\end{array}$ & \multirow[t]{2}{*}{$\begin{array}{c}\text { Customer Segments } \\
\text { Penikmat Musik Pop \& Rock }\end{array}$} \\
\hline & $\begin{array}{c}\text { Key Resource } \\
\text { Musisi } \\
\text { Studio Rekaman }\end{array}$ & & $\begin{array}{c}\text { Channels } \\
\text { Label Rekaman }\end{array}$ & \\
\hline \multicolumn{2}{|c|}{$\begin{array}{l}\text { Cost Structure } \\
\text { Label Rekaman }\end{array}$} & & \multicolumn{2}{|c|}{$\begin{array}{l}\text { Revenue Streams } \\
\text { Royalti } \\
\text { Konser Musik } \\
\text { Duta Merek }\end{array}$} \\
\hline
\end{tabular}

Gambar 2. Model Bisnis Musisi. 
Sebagian besar seniman global menjual lagu melalui iTunes dengan pembagian royalti yang akan diberikan kepada iTunes sebagai pengecer dan label. Misalnya Adele yang menandatangani kontrak dengan Sony Music untuk menjual lagu Rolling in the Deep seharga \$1.29 di iTunes. Apple sebagai pengecer mendapatkan 39 sen, sisanya 90 masuk ke aliran Sony. Label rekaman mengurangi 9.1 sen sebagai royalti mekanis yang akan dibayarkan kepada Adele dan penulis. Kontrak rekaman ini memberikan artis 12 hingga 20 persen dari seluruh penjualan yang bervariasi tergantung pada nilai ketenaran musisi [5]. Sejumlah besar royalti mengalir ke iTunes sebagai pengecer dan perusahaan rekaman sebagai penerbit musik, sedangkan musisi dan penulis lagu mendapatkan sebagian kecil dari royalti. Selain konser, royalti menjadi salah satu sumber pendapatan bagi musisi.

Indonesia memiliki YKCI sebagai lembaga yang bertugas untuk mengumpulkan hak karya cipta karena memiliki kekuatan hukum sebagaimana ditugaskan oleh penulis lagu Indonesia dan mewakili kepentingan ribuan penulis di seluruh Indonesia yang berkaitan untuk mengumpulkan hak atau performing rights. Yayasan Karya Cipta Indonesia (YKCI) telah berperan melakukan pengumpulan hak karya cipta selama 24 tahun namun belum dapat memberikan dampak kepada musisi di Indonesia mengenai royalti yang seharusnya dikumpulkan untuk dibagikan. Menurut WIPO, hak yang harus dipantau oleh lembaga kolektif adalah hak pertunjukan publik, hak siar, hak mesin reproduksi, hak tampil dalam karya drama, dan hak reproduksi reprografi (Fotokopi) [6]. Lisensi musik dirancang untuk memenuhi kebutuhan penulis lagu pada saat mereka tidak lagi produktif dalam bidang musik. Bentuk lisensi musik sama seperti dana pensiun atau asuransi. Jumlah royalti yang diterima oleh penulis masih belum diberikan detail secara terperinci kepada publik.

Paper ini merekomendasikan model bisnis yang tepat dan dapat dijadikan acuan untuk masa depan. Kami menggunakan model bisnis kanvas untuk dapat memetakan bagaimana model bisnis yang tepat dan dapat dijelaskan secara terperinci. Dengan cara ini, kita akan mendapatkan gambaran model bisnis dimana semua orang dapat mengerti karena konsep yang akan dihasilkan lebih sederhana, relevan, dan intuitif untuk dapat dipahami, sementara tidak menyederhanakan kompleksitas.

\section{2) Implementasi Model Bisnis}

Model bisnis merupakan abstraksi tentang bagaimana suatu bisnis berjalan dan kesederhanaan dari model bisnis diharapkan dapat mewakili kompleksitas aktivitas bisnis yang terjadi. Dengan adanya model bisnis, diharapkan kita dapat memahami hal - hal umum atau penting dari bisnis tersebut, tanpa terjebak ke dalam aktivitas yang bersifat mendetail. Sebuah model bisnis menggambarkan dasar pemikiran tentang bagaimana organisasi menciptakan, memberikan, dan menangkap nilai [7]. Model bisnis merupakan cetak biru sebuah strategi yang diterapkan melalui struktur organisasi, proses, dan sistem. Model bisnis digunakan sebagai alat pembanding model - model bisnis lainnya agar dapat mengenali perbedaan - perbedaan strategis yang dapat memberikan keunggulan kompetitif. Nilai lebih yang terdapat pada konsep model bisnis yaitu dapat menjadi salah satu alat bantu untuk menentukan keputusan strategis perusahaan. Perusahaan terkadang tidak memiliki pemahaman intuitif tentang model bisnis perusahaannya sendiri, sedangkan model bisnis dapat berpengaruh terhadap seluruh keputusan penting perusahaan. Belum banyak diketahuinya perangkat yang berguna untuk menilai, memahami, mengukur, mengubah, atau bahkan mensimulasikan model bisnis telah mempersulit individu atau pun organisasi dalam menggambarkan atau pun mendiskripsikan model bisnisnya.

Konsep model bisnis seharusnya dapat menjadi bahasa bersama yang memungkinkan untuk mendeskripsikan dan memanipulasi model bisnis dengan mudah agar tercipta alternatif strategi yang baru. Tanpa adanya kesamaan bahasa, tentu akan sulit bagi kita untuk secara sistematis membuat asumsi - asumsi tentang suatu model 
JURNAL

MANAJEMEN

INDONESIA

Vol. 14. No. 2

Agustus 2014 bisnis dan melakukan inovasi dengan sukses. Bisnis Model Kanvas dapat membantu untuk menterjemahkan model bisnis sehingga dengan kesamaan bahasa model bisnis, sebuah konsep model bisnis dapat dipahami, memfasilitasi deskripsi dan diskusi. Model Bisnis Kanvas terbagi menjadi 9 blok bangunan dasar yang diciptakan oleh Osterwalder untuk memperlihatkan cara berfikir tentang bagaimana sebuah perusahaan dapat menghasilkan uang. Model Bisnis Kanvas merupakan alat bantuk untuk mendiskripsikan, menganalisis, dan merancang model bisnis [7].

Penerbit Musik (Music Publisher) bertanggung jawab untuk membayar penulis lagu dan komposer yang karya - karyanya akan digunakan secara komersial. Tugas pokok mereka adalah utuk melisensi komposisi, dan memantau dimana komposisi atau lagu mereka dimainkan. Peran lainnya adalah mengumpulkan royalti dari masyarakat seluruh dunia. Penerbit musik menghubungkan lagu dengan artis rekaman yang cocok untuk dapat merekam, menempatkan lagu - lagu di media lain seperti soudtrack film, iklan, dan lain - lain [8]. Sebanyak 3 perusahaan rekaman terdaftar di ASIRI (Asosiasi Industri Rekaman Indonesia) memiliki saluran distribusi terluas untuk menjangkau pasar dengan berbagai varian produk yang ditawarkan, sehingga hanya tiga perusahaan rekaman tersebut yang mendominasi pasar. Ketiganya adalah Aquarius Musicindo, Musica Studios, dan Trinity Optima Production.

Peran pelaku bisnis pada Industri Musik dapat didefinsikan seperti pada gambar 2. Royalti setiap eksemplar yang terjual dari sebuah lagu, soundtrack, dimainkan di berbagai media, atau pertunjukan akan secara langsung diberikan kepada penerbit musik yang secara administratif menyalurkan royalti kepada pemegang hak.

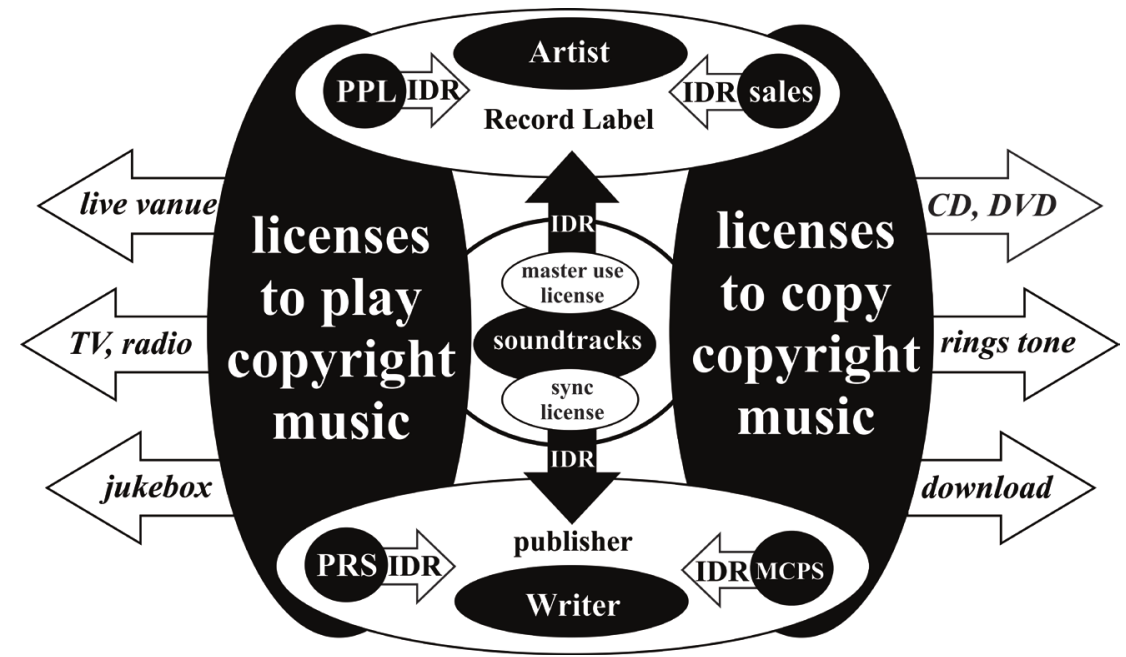

Gambar 3. Alur Kerja Pelaku Bisnis Industri Musik di Indonesia [9].

- The mechanical copyright protection society (MCPS) merupakan Asosiasi perlindungan hak cipta. Sebuah organisasi yang mengumpulkan royalti khususnya dari penjualan musik (CD dan download) bersama dengan loyalti yang dikumpulkan dari karya - karya yang menggunakan musik sebagian dari soundtrack mereka. Contohnya Soundtrack pada film. Setelah itu, MPC mengalokasikan pembayaran kepada komposer, penulis lagu, dan penerbit atas royalti yang mereka dapatkan.

- The performing right society (PRS) merupakan lembaga hak pertunjukan yang bertugas mendapatkan pembayaran dari setiap kinerja publik musik, baik langsung, rekaman, dari siaran radio atau pun televisi, atau online

- Phonographic Performance Limited (PPL) merupakan rekaman suara yang khusus dibuat untuk diputar oleh banyak stasiun radio atau lembaga penyiaran secara legal baik melalui rekaman suara maupun video musik atau Video Performance Limited (VPL) yang juga merupakan bagian dari PPL. 
Kami memetakan model bisnis melalui model bisnis kanvas yang dibagi menjadi 9 topik pertanyaan berdasarkan setiap blok kepada 7 narasumber dimana 4 diantaranya adalah penerbit musik dan 3 lainnya adalah sebagai penulis lagu dan juga musisi. Ketiga penerbit musik tersebut adalah Imam Sastrosatomo dari Aquarius Musikindo, Joseph Lumban Gaul pemilik M-stars Group, beserta Idham Hadiwisastra dan Anna k. Azzahra.dari Fast Forward Records. Sedangkan 3 penulis lagu yang juga merangkap sebagai musisi adalah Muhammad Amil Hussein dari Naif, Farri Icksan Wibisana dari The S.I.G.I.T. Band, dan Eross Candra dari Sheila On 7. Para narasumber yang berada dibidang music publishing memiliki pengalaman dalam pengimplementasian bisnis musik dan memiliki pengetahuan yang sangat lengkap mengenai perubahan atau penyesuaian Industri Musik Indonesia pada era digital saat ini. Sedangkan untuk narasumber songwriters yang sekaligus musisi adalah narasumber yang mengetahui proses perkembangan dari Industri Musik dari sisi songwriter sehingga dapat membantu untuk memotret keadaan sesudah dan sebelum proses perkembangan Industri Musik dalam Teknologi Informasi Komunikasi (TIK). Selain itu, kedua narasumber tersebut mampu memberikan informasi untuk melakukan evaluasi pada model bisnis dari penerapan kreatifitas dalam bisnis musik dimana proses bisnis musik tidak hanya terlaksana di Indonesia namun juga di pasar global

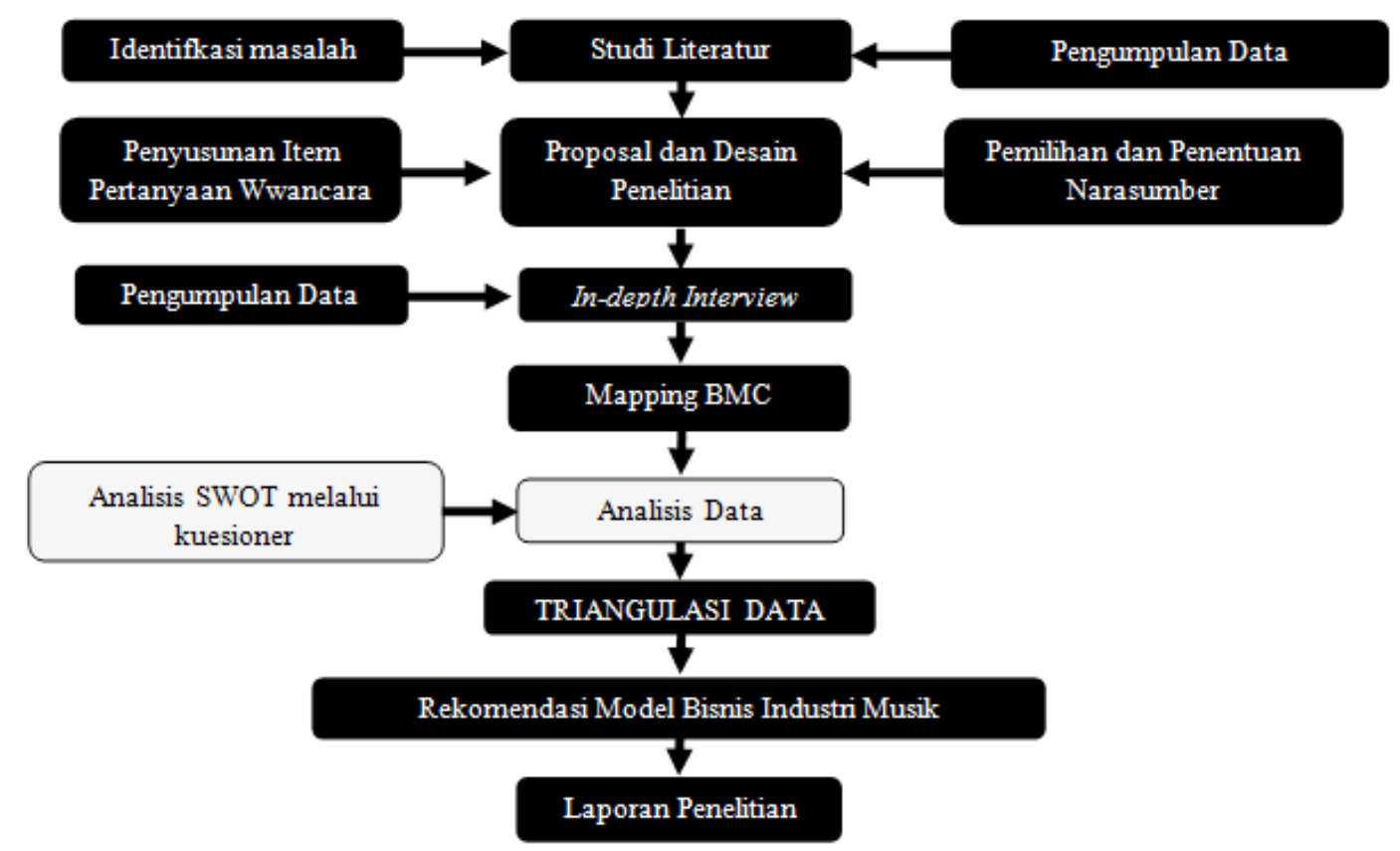

Gambar 4. Model Bisnis Penerbit Musik.

Teknik Validitas wawancara yang dilakukan melalui triangulasi sumber dengan melakukan wawancara melalui beberapa sumber. Kemudian untuk mendukung data dalam penelitian ini menggunakan kuesioner yang bertujuan untuk mendapatkan data Analisis SWOT. Pengujian validitas kuesioner menggunakan content validity yang melalui validasi oleh beberapa sumber ahli. Instrumen kuesioner dianggap reliable karena telah diadopsi oleh beberapa penelitian dan dijadikan Osterwalder sebagai alat evaluasi model bisnis perusahaan.

Analisis SWOT nantinya akan dibagi kedalam tiga kelompok yaitu strenght-weakness, opportunity, dan threat yang digunakan untuk mengevaluasi value proposition, cost-revenue, infrastructure, dan costumer interface pada aktivitas bisnis pada industri musik di Indonesia.

Pada kelompok Value Preposition akan menggunakan blok value prepositions sebagai unsur pertanyaan pada kuesioner. Sedangkan pada kelompok Cost-Revenue 


\section{JURNAL \\ MANAJEMEN \\ INDONESIA}

Vol. 14. No. 2

Agustus 2014 akan menggunakan blok revenue stream dan cost structure sebagai bahan acuan pada kuesioner. Untuk kelompok Infrastructure akan menggunakan blok key resource, key activity, dan key partnership. Dan pada kelompok Customer Interface akan menggunakan blok customer segments, channels, dan customer relationship.

Open Innovation Thinking digunakan untuk menganalisis setiap blok dengan memberikan kode pada setiap blok dan dievaluasi dengan menggunakan analisis SWOT dari 4 sektor. Penggabungan kekuatan, kelemahan, peluang dan ancaman, analisis SWOT menyediakan empat perspektif untuk menilai unsur - unsur model bisnis, sedangkan Model Bisnis Kanvas menyediakan fokus yang diperlukan untuk diskusi secara terstruktur. Hal ini digunakan untuk menganalisis kekuatan dan kelemahan organisasi dan mengindentifikasi peluang dan potensial ancaman. Analisis SWOT digunakan dalam proses evaluasi melalui kuesioner kepada 30 responden yang menjadi pelaku bisnis di Industri Musik dengan empat topik yang membantu menentukan rekomendasi model bisnis pada Industri Musik.

\section{4) Pengolahan Data}

Dalam proses pengolahan data dibagi menjadi 2 kategori yaitu music publisher dan songwriters. Pertimbangan ini didasarkan pada perbedaan model bisnis yang dilakukan keduanya sehingga tidak memungkinannya untuk digabungkan menjadi satu.

a) Analisis SWOT

Tabel.1

Analisis SWOT Business Model Canvas

\begin{tabular}{|c|c|}
\hline Strenghts & Weaknesses \\
Hubungan Pelanggan & Sumber Daya \\
Nilai Produk & Pembiayaan Bisnis \\
Mitra Bisnis & Saluran(Channels) \\
\hline Opportunities & Threats \\
Pendapatan & Pesaing \\
Teknologi & Pelanggan atau Pelanggan Baru \\
\hline
\end{tabular}

Kekuatan yang dimiliki oleh Industri Musik pada tabel 1 adalah bentuk hubungan pelanggan yang kuat dengan konsumen. Ini disebabkan karena mitra berperan aktif dalam proses implementasi bisnis, sehingga dengan nilai produk yang kuat dan didukung oleh mitra yang aktif, internal bisnis dapat berjalan sedemikian baik dan menciptakan hubungan pelanggan yang kuat. Mitra hanya berperan aktif dalam proses implementasi bisnis namun hanya memiliki sumberdaya yang terbatas. Selain itu, pembiayaan bisnis sulit untuk diprediksi mengingat perkembangan teknologi yang semakin maju. Saluran yang tercipta dengan baik pun masih sulit untuk dapat dijangkau oleh pelanggan. Hal inilah yang menjadi kesenjangan antara nilai yang ada dengan pelanggan. Masih belum adanya saluran yang dapat memfasilitasi pelanggan potensional lainnya sehingga proses ekspansi bisnis akan berjalan lambat.

Aktivitas kunci sulit untuk ditiru oleh pesaing, namun pesaing memiliki nilai lain sebagai kebutuhan substitusi pelanggan. Jika hal ini terjadi terus menerus, maka pesaing akan mengikis jumlah pelanggan yang ada. Sedangkan pelaung kemajuan teknologi dan pendapatan yang berulang dari pelanggan dapat menjadi dukungan untuk menutup kekurangan saluran. Pendapatan dapat mendukung terciptanya saluran baru yang berorientasi pada kemajuan teknologi dan sesuai dengan kebutuhan dan mudah diakses oleh pelanggan maupun konsumen potensional. 
Rekomendasi Model Bisnis Kanvas Untuk Musisi

\begin{tabular}{|c|c|c|c|c|}
\hline $\begin{array}{c}\text { Key Partners } \\
\text { Yayasan Karya Cipta Indonesia }\end{array}$ & $\begin{array}{c}\text { Key Activities } \\
\text { Produksi Lagu }\end{array}$ & $\begin{array}{c}\text { Value Propositions } \\
\text { Penampilan Panggung } \\
\text { Tata Suara Konser Musik }\end{array}$ & $\begin{array}{c}\text { Customer Relationships } \\
\text { Manajemen Penggemar }\end{array}$ & $\begin{array}{c}\text { Customer Segments } \\
\text { Penikmat Musik Non Pembeli }\end{array}$ \\
\cline { 2 - 4 } & $\begin{array}{c}\text { Key Resource } \\
\text { Penggemar Musik Pop dan Rock }\end{array}$ & $\begin{array}{c}\text { Channels } \\
\text { Label Rekaman }\end{array}$ & \multicolumn{2}{c|}{$\begin{array}{c}\text { Revenue Streams } \\
\text { Merchandise }\end{array}$} \\
\hline
\end{tabular}

JURNAL

MANAJEMEN

INDONESIA

Vol. 14. No. 2

Agustus 2014

\section{Gambar 5. Model Bisnis Penulis Lagu}

Jenis segment pelanggan penikmat musik yang sekaligus pembeli merupakan segementasi utama dari penulis lagu karena penjualan produk musik hanya diapresiasi oleh jenis segmen ini. Hal ini dikarenakan kurangnya pemahaman penulis lagu akan konser musik yang merupakan sebuah produk musik sehingga konser musiklah yang menjadi bagian pendapatan terbesar dari keseluruhan pendapatan yang ada. Segmen Konsumen yang berorientasi hanya untuk para penggemar musik bergenre pop dan rock akan membatasi jaringan penyebaran, sedangkan konsumen yang tdak membeli produk dikategorikan sebagai bukan jenis konsumen. Jika jumlah penggemar yang bukan pembeli dalam kuantitas yang besar, maka akan menimbulkan demand konser musik. Deskripsi ini berdasarkan model bisnis long tail yang diciptakan oleh Anderson tentang menjual sedikit dari banyak jenis produk. Total penjualan barang - barang ceruk dapat sama menguntungkannya karena sejumlah kecil yang terbaik berperan besar terhadap mayoritas pendapatan [10]. Perkembangan jumlah ilegal download membuat sebagian besar masyarakat dapat memperoleh musik dari berbagai macam media. Hal ini menyebabkan sejumlah penggemar tercipta dan dikelola oleh manajemen musisi. Konser Musik juga dapat tercipta berkat dorongan sejumlah besar penggemar yang tercipta berkat beberapa industri lain seperti telekomunikasi, maupun industri lainnya. Dengan begtitu, orientasi proporsi nilai harus berubah, nilai lain harus tercipta secara langsung untuk pelanggan dan pelanggan potensial.

Konser musik tidak hanya akan menjadi konser musik biasa karena musisi dituntut untuk menciptakan personal brand dari produk musik pada konser mereka. Secara teknis, desain panggung dan tata suara akan mempengaruhi penciptaan value yang mengarah ke citra baik atau buruknya musisi. Sebanyak $73 \%$ responden menuntut kebutuhan untuk kualitas suara yang lebih baik di konser, $71 \%$ responden merespon kebutuhan dekorasi yang menarik pada panggung tempat diadakannya konser [11]. Hal ini sebagai dasar bahwa konser pertunjukan musik merupakan bagian dari produk.

Value yang mampu diciptakan oleh musisi apabila dapat menarik banyak penggemar dapat memberikan dampak pendapatan lainnya pada brand ambassador untuk merek tertentu yang memiliki kecocokan dengan personalisasi dari musisi. Menjadi brand ambassador secara personal maupun dalam satu band akan memberikan umpan balik dalam bentuk pendapatan lainnya, juga akan mendapatkan pelanggan baru.

Sumber daya utama tidak hanya terfokus pada proses pembuatan lagu, tetapi pada fans. Penggemar adalah sumber daya utama bagi musisi untuk dapat tetap berada pada Industri Musik. Pendapatan yang didapatkan oleh penulis lagu ketika memutuskan pensiun dari bisnis musik akan berkurang karena penulis lagu berhenti membuat produk musik. Proses penarikan royalti oleh lembaga YKCI tidak memiliki dampak secara finansial bagi penulis lagu. Sehingga ketika proses kreatif dalam produksi lagu lagu sudah berhenti, maka konser musiklah yang dijadikan pendapatan utama di masa tua. 
Rekomendasi Model Bisnis Kanvas Untuk Penerbit Musik

Vol. 14. No. 2

Agustus 2014

\begin{tabular}{|c|c|c|c|c|}
\hline $\begin{array}{c}\text { Key Partners } \\
\text { Aneka Industri }\end{array}$ & $\begin{array}{c}\text { Key Activities } \\
\text { Pengembangan Musik }\end{array}$ & $\begin{array}{c}\text { Value Propositions } \\
\text { Musik dan Pertunjukan Digital }\end{array}$ & $\begin{array}{c}\text { Customer Relationships } \\
\text { Penggemar Merek Dagang }\end{array}$ & $\begin{array}{c}\text { Customer Segments } \\
\text { Penikmat Musik Digital }\end{array}$ \\
\cline { 4 - 5 } & $\begin{array}{c}\text { Key Resource } \\
\text { Penggemar Musik Pop dan Rock }\end{array}$ & & $\begin{array}{c}\text { Channels } \\
\text { Platform Digital } \\
\text { Festival Musik }\end{array}$ & Revenue Streams \\
& & & $\begin{array}{c}\text { Berlangganan Musik Digital } \\
\text { Royalti Penerbit Musik }\end{array}$ \\
\hline
\end{tabular}

\section{Gambar 6. Model Bisnis Penerbit Musik}

Orientasi yang tetap sama untuk tetap mempertahankan jenis produk analog seperti CD, VCD, dan Kaset dengan penambahan seperti artwork, liner notes, lirik, atau baru baru ini video memberikan pendapatan yang cenderung kecil. Sebagian besar pendapatan dari merchandise dan pertunjukan langsung diberikan kepada seorang musisi. Untuk segmentasi penggemar musik digital, terdapat varian produk yang tersedia seperti pada iTunes dengan format Appe Lossless Audio Codec (ALAC), Digilive yang merupakan konser musik dalam bentuk streaming yang dapat menggantikan beberapa produk analog sebelumnya. Menurut survey kementrian komunikasi dan informatika Indonesia, sebanyak 57,88\% responden menggunakan internet dimana saja melalui ponsel. Sementara peringkat ke 4 pada kegiatan yang dilakukan di Internet adalah untuk mengunduh film, gambar, musik, menonton TV atau video sebanyak $46,98 \%$. Sedangkan youtube.com merupakan situs yang paling dicari setelah google, facebook, blogspot [12]. Sejumlah 52,88\% anak muda berumur dibawah 25 tahun menikmati musik melalui handphone [13]. Untuk itu, segmentasi pelanggan yang mengalami penambahan harus diikuti dengan perubahan saluran untuk menyampaikan dan mempertahankan nilai - nilai yang ada. Saluran musik digital dapat menggantikan gerai musik. Saluran pada masing - masing segmentasi pelanggan yang terlalu luas yaitu pada penikmat musik rock dan pop sedangkan saluran distribusi berfokus pada gerai - gerai mitra dengan mendistribusikan produk fisik sangat bertolak belakang dengan strategi awal pelaku bisnis. Varian dari saluran untuk penyampaian produk musik digital tidak banyak disediakan sehingga terjadi ketimpangan dan tidak mampu secara menyeluruh untuk memenuhi kebutuhan pelanggan. Disamping itu, produk musik tidak mengalami perkembangan yang signifikan agar dapat menyesuaikan dengan kebutuhan pelanggan sehingga semakin tidak relevan dimana antara kebutuhan pelanggan dengan saluran yang ada tidak sesuai.

Salah satu cara alternatif menggantikan gerai musik adalah menggantikannya dengan Industri consumer goods yaitu Indomart, Alfamart, KFC, McDonalds, dan lain - lain. Alasan utamanya adalah pola konsumerisme konsumen telah berubah, dimana mayoritas masyarakat tidak lagi mengunjungi toko musik yang membuat perusahaan rekaman megganti saluran bisnis. Perusahaan rekaman pun mulai menutup gerai musik dan menggantinya dengan menggunakan berbagai macam platform yang disediakan oleh berbagai negara seperti iTunes dan google play. Pemerintah Indonesia sendiri masih belum mendukung terciptanya platform digital sehingga potensi monopoli Industri Musik Indonesia oleh asing akan semakin meningkat. Penigkatan terjadi karena ketergantungan perusahaan yang harus meningkatkan pembiayaan untuk fasilitas ini yang berakibat akan ditimbulkannya penyisihkan sejumlah royalti dalam skala yang tidak besar untuk musisi dan penulis lagu.

Konsep pemasaran Kevin Roberts masih melekat pada perusahaan rekaman dimana sejumlah pelanggan yang sudah menggemari sebuah merek tertentu (lovemark) akan setia kepada setiap produk yang ditawarkan mengingat kualitas yang akan ditawarkan juga sesuai dengan kebutuhan pelanggan. Menurut Kevin Roberts, pe- 
langgan yang telah menyukai merek dagang (lovemark) pasti akan memberikan rasa hormat dan cinta mereka kepada varian produk yang ditawarkan. Hubungan antara lovemarks dan konsep penjualan lainnya melalui skema sederhana berdasarkan rasa hormat dan cinta, merek yang menarik, bahkan rasa hormat akan menjadi abadi, dan cinta adalah apa yang dibutuhkan untuk dapat menyelamatkan merek [14].

Sebagian besar perusahaan rekaman menjaring pemasok bahan baku dan pro-

(1)

JURNAL

MANAJEMEN INDONESIA

Vol. 14. No. 2

Agustus 2014 duksi sebagai mitra usaha dengan tujuan untuk dapat mengurangi biaya, sementara
operator telekomunikas dengan fasilitas yang dimilikinya menunjang proses penyampaian informasi dan nilai. Berbagai Industri lainnya juga dapat dijadikan mitra untuk dapat meningkatkan pendapatan karena menurut Joseph Lumabn Gaol, Industri Musik sangat elastis dan dapat menyatu dengan berbagai Industri lainnya. Pada akhirnya, fokus utama pendanaan dalam model bisnis ini adalah bagaimana agar dapat menciptakan platform secara mandiri tanpa menunggu peran aktif pemerintah dan tidak hanya berfokus pada proses produksi dan promosi. Perusahaan akan secara efisien menyalurkan nilai untuk segmentasi konsumen penggemar musik digital dan dapat mengoptimalisasikan hubungan dengan pelanggan, tidak terpengaruh oleh monopoli atau kebijakan yang dibuat oleh negara lain yang pada hakekatnya saat ini memiliki fasilitas platform sehingga aliran royalti dapat secara maksimal didapatkan oleh musisi dan penulis lagu tanpa campur tangan negara lain.

\section{5) Kesimpulan}

Berdasarkan potret Business Model Canvas dan tidak memperdebatkan hal yang tidak penting seperti halnya pembajakan yang sebenarnya terdapat cara untuk monetisasi musik di era digital diambil kesimpulan bahwa Industri Musik di Indonesia telah memilih strategi yang tepat untuk budaya yang dimiliki Indonesia mengingat infrastruktur yang tersedia masih belum mampu untuk dapat secara langsung beralih ke digital. Model Bisnis tersebut adalah masih berorientasi pada model bisnis tradisional namun sudah mulai untuk memasukkan nilai produk digital pada beberapa segmentasi pelanggan digital. Proses peralihan tersebut dapat secara terstruktur dipersiapkan mulai dari saat ini dengan membangun platform yang nyaman dengan kemudahan mengakses bagi segmentasi konsumen digital. Perusahaan rekaman dapat mengefisienkan pembiayaan produksi serta meningkatkan music experience pelanggan. Salah satu contoh nyata adalah dengan free model business yang menawarkan free-of-charge yang terkonsep seperti gratis. Biaya untuk mereplikasi dan mendistribusikan karya - karya telah dilakukan melalui internet dengan biaya yang mendekati nol sementara proses promosi dan pemberian nilai melalui Web tidak hanya untuk konsumen lokal, namun juga global. Kemudian untuk menemukan pendapatan dari streaming adalah dengan memberikan konten tambahan melalui pola belangganan yang sejumlah royaltinya dapat secara langsung mengalir ke penulis lagu, artis, dan perusahaan rekaman tanpa perlu pemotongan biaya yang dilakukan oleh penyedia platform. Sedangkan cara terbaik menanggulangi pelanggaran hak cipta dan download illegal adalah dengan melakukan penyelarasan dengan pola konsumerisme saat ini dan merubah ancaman menjadi peluang. 
Daftar Pustaka

JURNAL

MANAJEMEN

INDONESIA

Vol. 14. No. 2

Agustus 2014
Pangestu, Elka, Maria, Dr. (2008). Rencana Pengembangan 14 Subsektor Industri Kreatif Indonesia 2009 - 2015. Jakarta.

International Federation of the Phonographic Industry (IFPI). 2013. Digital Music Report 2013.

Asosiasi Industri Rekaman Indonesia (ASIRI). 2009.

Putranto, Wendi, (2014). Tenggelamnya Aquarius Mahakam. Rollingstone Magazine Indonesia, 2 Januari 2014.

Rollingstone magazine. 2011. "The New Economics of the Music Industry”. Amerika. WIPO. (2009). Collective Management. Retrieved 08 December 2014, from World Intellectual Property Right Organization: http://www.ompi.ch/aboutip/en/ about_collective_mngt.html\#P67_8306

Osterwalder, Alexander \& Yves Pigneur (2012). Business Model Canvas. United States of America : John Wiley \& Sons, Inc., Hoboken, New Jersey.

Peitz, Martin \& Waelbroeck, Patrick. 2004. An Economist 's Guide to Digital Music. bemuso.com. Retrieved 08 December 2014, from www.bemuso.com

Anderson, Chris, 2006. The Long Tail: Why the Future of Business Is Selling Less of More. United States: Hyperion.

Hiswara, Rima, 2010. Analysis of the influence of musical ability, musician's appearance, musical sound, stage appearance, facilities, audience interaction to customer satisfaction in live performances of music. Faculty of economics and business, Universitas Hidayatullah, Jakarta.

The Ministry of Communication and Informatics Indonesia. 2010. ICT Indicators Indonesia 2011. www.balitbang.depkominfo.go.id.

Kompas (harian), 4 Februari 2015.

Robers, Kevin. 2004. Lovemarks: The Future Beyond Brands. United Kingdom: power House Books. 